\title{
Caracterização de genótipos de soja-hortaliça por análise de componentes principais
}

\author{
Genotypes characterization of vegetable soybeans by using principal component analysis
}

\author{
Dora Enith Tobar-Tosse ${ }^{I^{*}}$ Renata Castoldi ${ }^{I I}$ Willame dos Santos Candido ${ }^{I}$ \\ Antonio Sergio Ferraudo ${ }^{\mathrm{III}}$ Hamilton Cesar de Oliveira Charlo ${ }^{\text {IV }}$ \\ Leila Trevisan Braz
}

\section{RESUMO}

O presente estudo teve como objetivo caracterizar genótipos de soja-hortaliça, por meio de características agronômicas, nutricionais e antinutricionais, utilizando-se a Análise de Componentes Principais. O experimento foi conduzido em condições de campo no Setor de Olericultura e Plantas Aromático-Medicinais na UNESP-FCAV. O delineamento experimental foi em blocos casualizados com cinco genótipos e quatro repetições. Avaliaram-se as variáveis: número de vagens por planta, número de sementes por vagem, massa fresca das vagens por planta (g), massa fresca de 100 sementes ( $g$ ), produtividade total estimada de grãos imaturos $\left(\mathrm{kg} \mathrm{ha}^{-1}\right)$, teor de umidade, proteinas, lipídeos, cinzas, carboidratos, isoflavonas e inibidores de tripsina Kunitz. As variáveis que contribuíram na discriminação dos genótipos no primeiro componente principal foram: peso total de vagens por planta, teor de proteinas, número de vagens por planta, peso de 100 sementes e teor de umidade, enquanto que aquelas que contribuíram no segundo componente principal foram: teor de cinzas, proteinas, número de vagens por planta e teor de lipídeos. Os genótipos JLM010, JLM024 e CNPSO1, destacaram-se por serem influenciados pelo peso total de vagens por planta, produtividade estimada, número de vagens por planta, teor de carboidratos, isoflavonas e de proteinas, sendo considerados genótipos de soja-hortaliça com potencial para serem utilizados em programas de melhoramento genético vegetal.

Palavras-chave: discriminação multivariada, edamame, caracteres agronômicos, características nutricionais, características antinutricionais.

\section{ABSTRACT}

This study presents the characterization of vegetable soybean genotypes. It was applied Principal Component Analysis considering the agronomics, nutritional and antinutritional features: number of pods per plant, number of seeds per pod, fresh weight of pods per plant ( $g$ ), fresh weight of 100 seeds ( $g$ ), estimated total yield of immature seeds $\left(\mathrm{kg} \mathrm{h}^{-1}\right)$, moisture content, proteins, lipids, ash, carbohydrates, isoflavones and Kunitz trypsin inhibitor. The experiments were developed in the sector of Olericultura and Plantas Aromático-Medicinais from UNESP-FCAV. The results showed that fresh weight of pods per plant, proteins content, number of pods per plant, fresh weight of 100 seeds, and moisture content were the relevant variables for the discrimination of the genotypes in the first principal component and for the second principal the component were ash content, proteins, number of pods per plant and lipids content. Accordingly, the genotypes JLM010, JLM024 and CNPSO1 were defined as relevant by the variables fresh weight of pods per plant, estimated total yield of immature seeds, number of pods per plant, carbohydrates content, isoflavones and proteins. It was concluded that it is a relevant result because these genotypes were considered candidates to be used in plant breeding programs.

Key words: multivariate discrimination, edamame, agronomics features, nutritional features, antinutritional features.

\section{INTRODUÇÃO}

A soja-hortaliça ou verde [Glycine $\max$ (L.) Merrill] é a soja comum, que pode ser consumida de maneira direta quando as sementes ainda estão imaturas, segundo ZHANG et al. (2010), no estádio R6-R7, e atualmente esta hortaliça é considerada nutritiva e saudável, principalmente porque suas sementes contém por volta de $33 \%$ a $39 \%$ e de $13 \%$ a $16 \%$ de proteína e óleo, respectivamente (RAO et

IDepartamento de Produção Vegetal, Universidade Estadual Paulista (UNESP), Via de Acesso Prof. Paulo Donato Castellane s/n, 14884-900, Jaboticabal, SP, Brasil. E-mail: detobart@unal.edu.co. *Autor para correspondência.

IIUnidade de Passos, Universidade do Estado de Minas Gerais (UEMG), Passos, MG, Brasil.

IIIDepartamento de Ciências Exatas, UNESP, Jaboticabal, SP, Brasil.

IVInstituto Federal do Triângulo Mineiro (IFTM), Uberaba, MG, Brasil. 
al., 2002). Além disso, a presença de isoflavonas é associada com a geração de efeitos protetivos contra câncer de mama, próstata e cólon (POOL-ZOBEL et al., 2000; VASTAG, 2007; KANG et al., 2010).

Em programas de melhoramento genético de soja-hortaliça, as principais características desejáveis são alto rendimento e qualidade (SARUTAYOPHAT, 2012). Segundo CARRÃO-PANIZZI et al. (2009), é importante avaliar germoplasmas, com o intuito de selecionar genótipos com sabor mais adocicado (baixo ou sem conteúdo de lipoxigenases), tamanho graúdo das sementes, hilo amarelo, alto conteúdo de proteínas, isoflavonas, saponinas, tocoferóis, baixo teor do inibidor de tripsina (reduzindo o tratamento térmico) e, ácidos graxos oleico e linoleico em baixas quantidades. As cultivares de soja 'BRS 267' e 'BRS MG 790', desenvolvidas pela Embrapa-Soja, podem ser consumidas como edamame, já que apresentam sementes graúdas ( $>25 \mathrm{~g} 100$ sementes $\left.^{-1}\right)$, com cor de hilo amarelo e sabor superior, quando em estádio imaturo $\mathrm{R}_{6}$.

As técnicas de análises multivariadas são importantes ferramentas para classificar germoplasmas, ordenar variabilidades contidas em acessos, bem como analisar relações genéticas entre características e materiais vegetais melhorados (IQBAL et al., 2008). Com estas informações, é possível identificar populações com potencial para obter híbridos, pois, segundo OLIVEIRA (1989), as avaliações do material genético sobre um conjunto de características combinam as múltiplas informações contidas na unidade experimental, facilitando, dessa forma, a seleção de materiais promissores e avaliação da divergência genética. Dentre as técnicas multivariadas, a Análise de Componentes Principais (ACP) é uma metodologia poderosa para discriminar acessos, que reduz o número de variáveis a um número limitado de novas variáveis, que são os Componentes Principais (CP). Ao contrário das variáveis medidas, os $\mathrm{CP}$ são ortogonais. Cada $\mathrm{CP}$ é responsável pela representação de um percentual da variância dos dados, sendo ideal que, no resultado final, parte relevante da variabilidade seja representada por, no máximo, três CP (HAIR et al., 2005).

Dada a importância da soja-hortaliça como alimento, este estudo teve por objetivo caracterizar os genótipos JLM003, JLM004, JLM010, JLM024 e CNPSOI por suas características agronômicas, nutricionais e antinutricionais, para serem utilizados em programas de melhoramento genético vegetal. Para isso, foi aplicada a Análise de Componentes Principais, utilizada para filtrar as informações consideradas relevantes, contidas no conjunto original de variáveis em conjuntos de menores dimensões.

\section{MATERIAL E MÉTODOS}

O experimento foi conduzido na área experimental da Faculdade de Ciências Agrárias e Veterinárias, Câmpus de Jaboticabal-SP (UNESPFCAV), localizada nas coordenadas $21^{\circ} 14^{\prime} 05^{\prime \prime} \mathrm{S}$, $48^{\circ} 17^{\prime} 09^{\prime}$ " W e altitude de $614 \mathrm{~m}$.

O delineamento experimental utilizado foi em blocos casualizados, com cinco genótipos e quatro repetições. Os genótipos utilizados foram selecionados com base na produção e qualidade dos grãos imaturos, adquiridos em ensaios realizados anteriormente na mesma área experimental (CHARLO et al., 2008; CASTOLDI et al., 2008; CASTOLDI et al., 2009a; CASTOLDI et al., 2009b), consistindo dos seguintes materiais: JLM003, cedido do banco de germoplasma da Embrapa Hortaliças, apresentam sementes de tamanho médio, peso seco de 100 sementes, equivalentes a $30 \mathrm{~g}$, flor roxa, hilo e grão amarelo; JLM004, cedida pela Embrapa Hortaliças, suas sementes possuem tamanho médio, peso seco de 100 sementes de $37 \mathrm{~g}$, flor roxa e hilo de coloração marrom; JLM010, cedido pelo órgão Desenvolvimento de Pesquisa Vegetal da Ásia, Taiwan, possuem tamanho médio de sementes, peso seco de 100 sementes de $41 \mathrm{~g}$, flor branca e hilo e sementes de coloração amarela; JLM024, cedida pelo banco de germoplasma da Embrapa Cenargem, apresentam plantas de porte alto e peso seco de 100 sementes de $19 \mathrm{~g}$ e; CNPSOI, cedida pelo banco de germoplasma da Embrapa Soja, apresentam sementes de tamanho médio, peso seco de 100 sementes de $27,8 \mathrm{~g}$ e hilo de coloração amarela.

Cada parcela experimental foi constituída de quatro linhas de $6 \mathrm{~m}$ de comprimento, $0,60 \mathrm{~m}$ entre linhas e $0,15 \mathrm{~m}$ entre plantas. Em cada parcela, 20 plantas das duas linhas centrais foram avaliadas para todas as características. O local foi preparado conforme sistema convencional, antes do transplante, consistindo de duas arações, uma gradagem, e adubação de plantio, de acordo com a análise química do solo e recomendações técnicas para a cultura da soja (RAIJ et al., 1997).

As colheitas foram realizadas quando as vagens estavam em estádio reprodutivo $\mathrm{R}_{6}$, utilizando-se a escala de referência de FEHR \& CAVINESS (1977), adaptada por COSTA \& MARCHEZAN (1982). As plantas foram cortadas logo acima da superfície do solo e conduzidas ao laboratório, onde foram removidas as vagens e avaliaram-se: número de vagens por planta, número de sementes por vagem, peso fresco total de vagens por planta, peso fresco de 100 sementes e produtividade estimada de grãos imaturos em $\mathrm{kg} \mathrm{ha}^{-1}$. 
No Laboratório de Genética e Melhoramento de Plantas da Embrapa Soja, de acordo com o proposto em AOCS (1988), avaliou-se, nas sementes: teor de umidade, determinado pelo método gravimétrico; a porcentagem de proteínas, quantificada pelo método micro Kjeldahl, a porcentagem de lipídeos, determinados por extração de Soxhlet, e a porcentagem de Cinzas, através da incineração completa da amostra num forno de mufla, com temperatura inicial de $150^{\circ} \mathrm{C}$, e aumento de 50 a $50^{\circ} \mathrm{C}$ a cada 30 minutos, até chegar à temperatura final de $550^{\circ} \mathrm{C}$; e a porcentagem de carboidratos, que foi determinado por diferença; teor de isoflavonas, quantificadas por cromatografia líquida de alto desempenho (HPLC), seguindo o método do BERHOW (2002) e inibidor de Tripsina Kunitz, determinado em extratos obtidos a partir de farinha desengordurada, usando um padrão de tripsina com BPNA como substrato e leitura da absorbância a $X=410 \mathrm{~nm}$, de acordo com a metodologia de KAKADE et al. (1974), alterado por HAMERSTRAND et al. (1981).

A caracterização dos genótipos foi feita utilizando-se a Análise de Componentes Principais, que é uma técnica multivariada exploratória. Foi processada com a matriz de covariância das variáveis originais, obtendo-se dela os autovalores que construíram os autovetores. Estes são combinações lineares das variáveis originais e se denominam componentes principais. O poder discriminatório de cada variável num componente foi medido pela fórmula:

$$
\mathbf{r}_{\mathbf{x j}}\left(\mathbf{c} \mathbf{p}_{\mathrm{h}}\right)=\frac{\mathbf{a}_{\mathrm{jh}} \sqrt{\lambda_{\mathrm{h}}}}{\mathrm{s}_{\mathrm{j}}}
$$

Nessa fórmula, $\mathbf{s}_{\mathbf{j}}=$ desvio padrão da variável $\mathrm{j}, \quad a_{j \boldsymbol{h}}=$ coeficiente da variável $\mathrm{j}$ no h-ésimo componente principal, e $\lambda_{\boldsymbol{h}}=\mathrm{h}$-ésima raiz característica (autovalor) da matriz de covariância (HAIR et al., 2005). Todas as análises foram processadas no programa STATISTICA, versão 7, após padronização das variáveis (média nula e variância unitária).

\section{RESULTADOS E DISCUSSÃO}

As análises mostraram que os dois primeiros componentes principais permitiram explicar 59,0\% da variância contida nas variáveis originais (Tabela 1). O componente principal 1 (CP1) e o componente principal 2 (CP2) contribuíram com 42,9\% e 16,1\%, respectivamente, da variância remanescente. $\mathrm{O}$ terceiro componente principal, embora com autovalor

\begin{tabular}{|c|c|c|}
\hline Componentes principais (CP) & $\mathrm{CP} 1$ & $\mathrm{CP} 2$ \\
\hline Contribuição dos CP (\%) & 42,9 & 16,1 \\
\hline Contribuição acumulativa (\%) & 42,9 & 59,0 \\
\hline № de vagens por planta & 0,6 & $-0,6$ \\
\hline № sementes por vagem & 0,0 & 0,3 \\
\hline Peso de 100 sementes & 0,5 & 0,2 \\
\hline Peso total de vagens por planta & 0,9 & $-0,2$ \\
\hline Produtividade estimada em $\mathrm{kg} \mathrm{ha}^{-1}$ & 0,7 & $-0,2$ \\
\hline Porcentagem de umidade & $-0,9$ & $-0,1$ \\
\hline Porcentagem de lipídeos & $-0,3$ & 0,6 \\
\hline Porcentagem de cinzas & 0,2 & 0,6 \\
\hline Porcentagem de proteínas & 0,7 & 0,6 \\
\hline Porcentagem de carboidratos & 0,9 & $-0,3$ \\
\hline Isoflavonas (mg $\left.100 \mathrm{~g}^{-1}\right)$ & 0,8 & 0,1 \\
\hline Inibidor de Tripsina ( $\left.\mathrm{mg} \mathrm{IT}^{-1}\right)$ & 0,3 & 0,4 \\
\hline
\end{tabular}

acima da unidade, não foi considerado, uma vez que não acrescentou informação relevante.

Foram consideradas como relevantes as cargas que apresentaram valor absoluto superior a 0,5 . Assim, na tabela 1 , as variáveis que apresentaram maior poder discriminatório em CP1 foram: o peso total de vagens por planta $(0,9)$, a porcentagem de carboidratos $(0,9)$, o teor de isoflavonas $(0,8)$, a produtividade total estimada de grãos imaturos em $\mathrm{kg}$ ha $(0,7)$, a porcentagem de proteínas $(0,7)$, o número de vagens por planta $(0,6)$, o peso de 100 sementes $(0,5)$ e a variável porcentagem de umidade $(-0,9)$. Variáveis com mesmo sinal atuam de forma direta, ou seja, quando o valor de uma aumenta, o valor da outra aumenta, ou vice-versa, e aquelas com sinais contrários atuam de forma inversa, ou seja, quando o valor de uma aumenta, o valor da outra diminui. Assim, as variáveis peso total de vagens por planta, a porcentagem de carboidratos, o teor de isoflavonas, a produtividade total estimada de grãos imaturos, a porcentagem de proteínas, o número de vagens por planta e o peso de 100 sementes atuam de forma direta e inversamente à umidade.

Ainda na tabela 1 , as variáveis com maior poder discriminatório em $\mathrm{CP} 2$ foram: a porcentagem de cinzas $(0,6)$, a porcentagem de proteínas $(0,6)$, a porcentagem de lipídeos $(0,6)$ e o número de vagens por planta $(-0,6)$. As três primeiras se associam de forma direta e inversamente à variável número de vagens por planta.

Assim, essas variáveis agronômicas e propriedades funcionais em destaque nos dois primeiros componentes principais $\mathrm{CP} 1$ e CP2 são 
consideradas importantes para a seleção de genótipos de soja-hortaliça, ideais para a região de Jaboticabal.

$\mathrm{Na}$ figura 1, pode-se observar que as correlações positivas são responsáveis pela discriminação dos genótipos localizados à direita de $\mathrm{CP} 1$ (JLM010, JLM024 e CNPSO1) e a correlação negativa pela discriminação dos genótipos, à esquerda de CP1 (JLM003 e JLM004). As variáveis com correlação positiva são as responsáveis pela discriminação dos genótipos localizados na parte superior de CP2 (JLM010, JLM024, JLM003 e JLM004) e as variáveis com correlação negativa são as responsáveis pela discriminação dos genótipos localizados na parte inferior de CP2 (CNPSO1). É possível observar que as variáveis associadas com o rendimento e aquelas associadas com características nutricionais e antinutricionais estão voltadas para a direita em CP1. Ao observar, na figura 1, a associação entre os grupos de variáveis e os genótipos de soja-hortaliça, vê-se que os genótipos JLM010 e JLM024 possuem potenciais a terem maiores valores de peso total de vagens por planta, porcentagem de carboidratos, isoflavonas, produtividade estimada em $\mathrm{kg} \mathrm{ha}^{-1}$, porcentagem de proteínas, peso de 100 sementes, menor peso e menor porcentagem de umidade. Também, quanto ao CP2, JLM010 e JLM024 apresentam potenciais, embora fraco, a terem maiores valores de porcentagem de cinzas e porcentagem de lipídeos. O genótipo CNPSO1, embora se localize do lado direito, tende a ter amostras com maior número de vagens por planta, diferenciando-se dos genótipos JLM010 e JLM024, que possuem menor valor.

Para que um genótipo de soja-hortaliça seja considerado apto para o consumo, e possa ser comercializado, deve ter alta produção e propriedades funcionais, tais como produção média de 50 a 70 vagens por planta (NGUYEN, 2001), sementes grandes que permitirão cozinhar e servir de alimento como uma hortaliça e porcentagens de proteína alta (CARRÃO-PANIZZI, 2006).

Com base nisso, e considerando os resultados das análises de componentes principais, os genótipos JLM003, JLM004 não apresentam características de consumo como soja-hortaliça, pois apresentaram maiores taxas de porcentagem de lipídeos e de umidade que os demais genótipos, e baixos valores das variáveis associadas ao rendimento. O genótipo CNPSOI apresentou associação com a variável número de vagens por planta $(0,6 \mathrm{com}$ CP1 e -0,6 com CP2). Porém, amostras de CNPSOI se localizaram à direita de $\mathrm{CP} 1$, o que o caracteriza também nos mesmos potenciais dos genótipos JLM010 e JLM024, com a diferença de que estes dois tendem a ter menor número de vagens por planta.

Os genótipos JLM010, JLM024 e CNPSOI (com as considerações quanto ao número de vagens/ planta) destacaram-se por expressar fenótipos

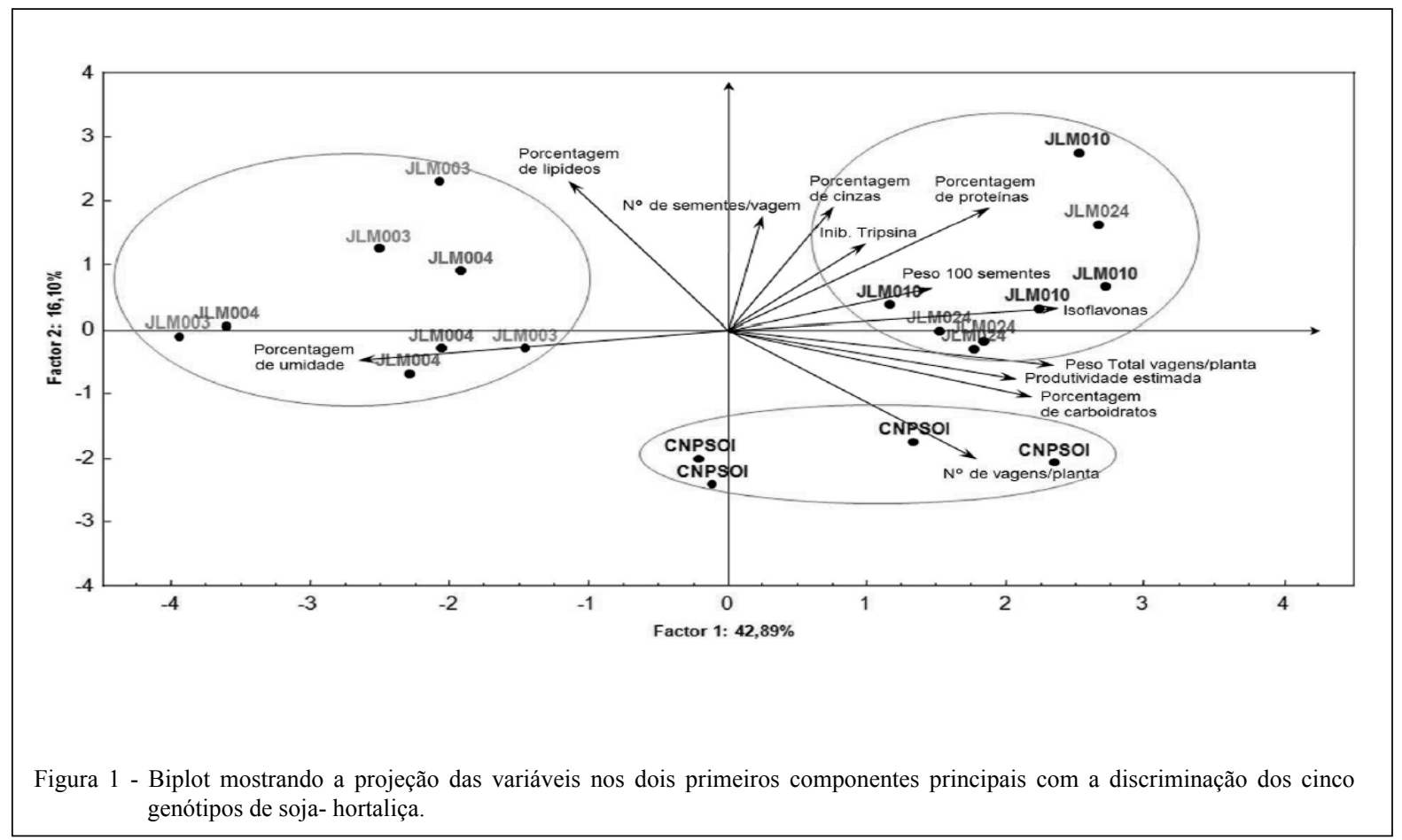

Ciência Rural, v.45, n.7, jul, 2015. 
influenciados pelas variáveis associadas à produção: peso total de vagens por planta $(0,9)$, produtividade estimada em $\mathrm{kg} \mathrm{ha}^{-1}(0,7)$, número de vagens por planta $(0,6)$ e aquelas associadas com as propriedades funcionais da soja, como: a porcentagem de carboidratos $(0,9)$, isoflavonas $(0,8)$ e a porcentagem de proteínas $(0,7)$, o que leva a considerar estes genótipos em condições de consumo como soja-hortaliça e com potencial para serem usados em programas de melhoramento genético vegetal. Com exceção da variável Número de Sementes por Vagem e Inibidor de Tripsina, todas as demais apresentaram poder discriminatório na caracterização dos genótipos. IQBAL et al. (2008), ao avaliarem em soja comum a porcentagem de óleo, o rendimento e outras características associadas a esta variável, também encontraram, de forma semelhante ao que foi identificado neste trabalho, que as variáveis que mais contribuíram no CP1 foram as relacionadas ao rendimento por planta $(1,0)$, indicando assim que as populações com valores maiores para o CP1 são altamente rentáveis; e a porcentagem de óleo $(0,8)$ apresentou uma maior contribuição também no $\mathrm{CP} 2$, mas o peso de 100 sementes $(0,7)$ contribuiu no $\mathrm{CP} 2$ e não no $\mathrm{CP} 1$, como apresentado neste trabalho.

A técnica de componentes principais tem sido utilizada para a caracterização de bancos de germoplasma de hortaliças, como coentro, cebola, e feijão (RODRIGUES et al., 2002; BARBIERI et al., 2005; MAGALHÃESBERTINI et al., 2010) e tem levado a identificar características importantes para serem avaliadas por meio de estudos prévios da sua contribuição para a variabilidade (PEREIRA, 1989). Isso tem permitido descartar caracteres de pouca contribuição para a discriminação dos genótipos avaliados e, dessa forma, é possível reduzir mão de obra, tempo e custos (CRUZ et al., 2004).

\section{CONCLUSÃO}

A Análise de Componentes Principais, como ferramenta exploratória, permitiu identificar as variáveis de rendimento e propriedades funcionais importantes na caracterização de genótipos para consumo como soja-hortaliça (peso total de vagens por planta, produtividade estimada, número de vagens por planta, porcentagem de carboidratos, isoflavonas (mg $\left.100 \mathrm{~g}^{-1}\right)$ e porcentagem de proteínas). Foi possível, assim, identificar os genótipos JLM010, JLM024, e CNPSOI com potencial para serem utilizados em programas de melhoramento genético.

\section{AGRADECIMENTOS}

À Fundação de Amparo à Pesquisa do Estado de São Paulo (FAPESP) pela bolsa de mestrado concedida à segunda autora (Processo № 05/58238-6) e Auxílio à Pesquisa (Processo № 05/58714-2).

\section{REFERÊNCIAS}

AOCS (AMERICAN OIL CHEMISTS SOCIETY). Official methods and recommended practices of the American Oil Chemists' Society. 3.ed. Champaign, 1988. V.1-2.

BARBIERI, R.L. et al. Divergência genética entre populações de cebola com base em marcadores morfológicos. Ciência Rural, v.35, n.02.p.303-308, 2005. Disponível em: $<$ http://www.scielo.br/ scielo.php?script=sci_arttext\&pid=S0103-84782005000200009>. Acesso em: 15 jan. 2014. doi: 101590/S0103-84782005000200009.

BERHOW, M.A. Modern analytical techniques for flavonoid determination. In: BUSLIG, B.S.; MANTHEY, J.A. (Eds.). Flavonoids in the living cell. New York: Klusher Academic, 2002. p.61-76. (Adv. Exp. Méd. Biol., v.505).

CARRÃO-PANIZZI, M.C. et al. Breeding specialty soybean cultivars for processing and value-added utilization at Embrapa in Brazil. In: WORLD SOYBEAN RESEARCH CONFERENCE, 8., 2009, Beijing. Abstracts... Beijing, 2009. p.1-4. Disponível em: $<$ http://ainfo.cnptia.embrapa.br/digital/bitstream/item/34299/1/ id30102.pdf>. Acesso em: 23 mar. 2013.

CARRÃO-PANIZZI, M.C. Edamame ou soja-hortaliça: fácil de consumir e muito saudável. Informe Agropecuário, v.27, p.59-64, 2006.

CASTOLDI, R. et al. Performance of different genotypes of vegetable soybeans in Jaboticabal-SP. IHC-S2 ASIAN PLANTS WITH UNIQUE HORT, XXVII. Potential Eds.-in-Chief: Donglin Zhang et al. Acta Horticulturae, 769, ISHS, 2008. Disponível em: <http://www.actahort.org/books/769/769_15.htm>. Acesso em: 10 dez. 2012.

CASTOLDI, R. et al. Influência do espaçamento entre plantas em características agronômicas de dois genótipos de soja-hortaliça de ciclo tardio em Jaboticabal-SP. Científica, v.37, n.2, p.61-66, 2009a. Disponível em: <http://www.cientifica.org.br/index.php/ cientifica/article/view/282>. Acesso em: 5 dez. 2012.

CASTOLDI, R. et al. Desempenho de quatro genótipos de sojahortaliça em dois anos agrícolas. Horticultura Brasileira, v.27, p.256-259, 2009b. Disponível em: <http://www.scielo. $\mathrm{br} / \mathrm{scielo} . \mathrm{php}$ ?pid $=\mathrm{S} 0102-05362009000200024 \&$ script $=\mathrm{sci}$ arttext>. Acesso em: 10 dez. 2012. doi:10.1590/S010205362009000200024 .

CHARLO, H.C. de. O. et al. Performance of genotypes of earlycycle vegetable soybeans [Glycine max (L.) Merril] in different densities. Ciência e Agrotecnologia, v.32, n.2, p.630 -634, 2008. Disponível em: <http://www.scielo.br/scielo.php?pid=S141370542008000200044\&script $=$ sci_arttext $>$. Acesso em: 15 mar. 2012. doi: $10.1590 / \mathrm{S} 1413-70542008000200044$.

COSTA, J.A.; MARCHEZAN, E. Características dos estádios de desenvolvimento da soja. Campinas: Fundação Cargill, 1982. 30p. 
CRUZ, C.D. et al. Modelos biométricos aplicados ao melhoramento genético. 3.ed. Viçosa: UFV, 2004. 1v. 480p.

FEHR, W.R.; CAVINESS, C.E. Stages of soybean development Ames: Cooperative Extension Service, 1977. 11p. (Special Report 80).

HAIR, Jr., J.F. et al. Análise multivariada de dados. 5.ed. Porto Alegre: Bookman, 2005. 592p.

HAMERSTRAND, G. E. Trypsin inhibitors in soy products: modification of the standard analytical procedure. Cereal Chemistry, v.51, p.42-45, 1981.

IQBAL, Z. et al. Evaluation of soybean [Glycine max (1.) Merrill] germplasm for some important morphological traits using multivariate analysis. Pakistan Journal of Botany, v.40, n.6, p.2323-2328, 2008. Disponível em: <http://www. pakbs.org/pjbot/PDFs/40(6)/PJB40(6)2323.pdf>. Accesso em: 10 dez. 2013

KAKADE, M.L et al. Determination of trypsin inhibitor analysis of an improved procedure. Cereal Chemistry, v.51, p.376-382, 1974.

KANG, X. et al. Effect of soy isoflavones on breast cancer recurrence and death for patients receiving adjuvant endocrine therapy. Canadian Medical Association Journal, v.182, n.17, p.1857-1862, 2010. Disponível em: <http://www.ncbi.nlm.nih. gov/pubmed/20956506>. Acesso em: 9 dez. 2013. doi: 10.1503/ cmaj.091298.

MAGALHÃES-BERTINI, C.H. et al. Desempenho agronômico e divergência genética de genótipos de coentro. Revista Ciência Agronômica, v.41, n.3, p.409-416, 2010. Disponível em: $\quad<$ http://www.scielo.br/scielo.php?script=sci arttext\&pid $=$ S1806-66902010000300013 $>$. Acesso em: 15 nov. 2013. doi: 101590/S1806-66902010000300013.

NGUYEN, V.Q. Edamame (vegetable green soybean). In: RURAL INDUSTRIES RESEARCH \& DEVELOPMENT. The new rural industries: a handbook for farmers and investors. Austrália, 2001. p.49-56, 2001

OLIVEIRA, E.J. de. Análise multivariada no estudo da divergência genética entre cultivares de feijão (Phaseolus vulgaris L.). 1989. 91f. Dissertação (Mestrado em Genética e Melhoramento) - Universidade Federal de Viçosa, Viçosa, MG.
PEREIRA, A.V. Utilização de análise multivariada na caracterização de germoplasma de mandioca (Manihot esculenta Crantz). 1989. 180f. Tese (Doutorado em Genética e Melhoramento de plantas) - Escola Superior de Agricultura "Luiz de Queiroz", Universidade de São Paulo, Piracicaba, SP.

POOL-ZOBEL, B.L. et al. Isoflavonoids and lignans have different potentials to modulate oxidative genetic damage in human colon cells. Carcinogenesis, v.21, n.6, p.1247-1252, 2000. Disponível em: <http://carcin.oxfordjournals.org/content/21/6/1247.full $>$. Acesso em: 8 dez. 2013. doi: 10.1093/carcin/21.6.1247.

RAIJ, B. et al. Recomendações de adubação e calagem para o Estado de São Paulo. Campinas: Instituto Agronômico de Campinas, 1997. 285p. (Boletim Técnico 100).

RAO, M. et al. Fresh green seed yield and seed nutritional traits of vegetable soybean genotypes. Crop Science, v.42, p.1950-1958, 2002. Disponível em: $<$ https://dl.sciencesocieties.org/publications/ cs $/$ abstracts $/ 42 / 6 / 1950$ ?access $=0 \& v i e w=p d f>$. Acesso em: 13 jul. 2012. doi: $10.2135 /$ cropsci2002.1950.

RODRIGUES, L.S. et al. Divergência genética entre cultivares locais e cultivares melhoradas de feijão. Pesquisa Agropecuária Brasileira, v.37, n.9, p.1275-1284, 2002. Disponível em: $<$ http://www.scielo.br/scielo.php?script=sci_arttext\&pid=S0100\#back1>. Acesso em: 20 nov. 2013. doi:10.1590/S0100204X2002000900011

SARUTAYOPHAT, T. Correlation and path coefficient analysis for yield and its components in vegetable soybean. Songklanakarin Journal of Science and Technology, v.34, n.3, p.273-277, 2012. Disponível em: <http://journaldatabase.org/articles/correlation path coefficient_analysisfor_yield_its.html>. Acesso em: 9 dez. 2013.

VASTAG, B. Soy and prostate cancer study results mixed. Journal of the National Cancer.Institute, v.99, n.18, p.13641365, 2007. Disponível em: <http://jnci.Oxfordjournals.org/ content/99/18/1364.full>. Acesso em: 9 dez. 2013. doi: 10.1093/ jnci/djm 162 .

ZHANG, Q.Y. et al. Influence of sowing date on phenological stages, seed growth and marketable yield of four vegetable soybean cultivars in Northeastern USA. African Journal of Agricultural Research, v.5, n.18, p.2556 - 2562, 2010. Disponível em: $<$ http://www.academicjournals.org/journal/AJAR/articleabstract/6E6678E34155>. Acesso em. 12 jul. 2012. 